\title{
Examining the Construction of Identity among High Performance Male and Female
}

\section{Athletes using Photography}

\begin{abstract}
This study, adopting a feminist perspective explored two research questions: 1 ) how do male and female athletes perform an athletic identity through photographic self-representation, and 2) what are the messages they look to convey, as role models, through these images? Eighteen culturally diverse high-performance athletes ( 12 female, six male; mean age $=20.56$ years, $S D=2.83)$ representing a range of sports took part. Following an individual photo session with autonomy over image capture, participants selected their favoured image and provided a caption symbolising the message they wished to convey to others. Participants were then interviewed to obtain their thoughts, feelings, and stories with regards image capture and selection. Analysis of photographic data revealed a tendency for participants to select full body action shots, located in the field of play, and wearing sports clothing. Captions emphasised hard work, psychological assets, technical precision, and encouraged sports participation. Interview data were organised under two broad themes aligned with the research questions; 'performing an athletic identity' and 'intended messages'. Participants typically wanted to appear in action shots, emphasising good technique, displaying a sporting physique, and in relevant uniforms. Intended messages reflected how to be a good role model and comprised of ideals of hard work and giving sport a go. Findings suggest that whilst athletes sought to champion their sport and the physical and psychological qualities that participation produces, gendered performances were also evident in production and interpretation of many images, thus highlighting the pervasive nature of gendered sporting participation.
\end{abstract}


Keywords: athletic-identity, gender performance, role-model, physicality, psychological strength

\section{Introduction}

The present study examines the use of photography in the construction of identity among high performance male and female athletes. The theoretical framework of the study begins with a feminist standpoint, in that it premises the notion that ideas around gender influence how sporting experiences are shaped and vice versa (Ross and Shinew 2008). The study specifically adopts a Foucaultian feminist perspective by embedding Foucault's (1972) concept of discourse and Butler's (1993) later work on gender performativity in helping to understand athletic identity negotiation. Discourse consists of certain sets of knowledge and social practices (Foucault 1972, 1978), such as cultural standards regarding appearance, behaviour, and values that shape understandings of what is considered feminine or masculine (Krane et al. 2004; McGannon and Spence 2012). Markula and Pringle (2006) note how this usage of discourse, as a 'regulated practice', shapes what can be understood about an activity but also what can be obscured. Butler (1990), drew on Foucault in arguing that gender is a form of forced cultural performance with the repetitions of gendered behaviours learnt over time to construct versions of ourselves that hold social value; this aspects applies particularly well for sport and constructed ways of 'being' certain types of athletes. Phoenix $(1997,5)$ suggests that males and females learn how to "do femininity" or "do masculinity" through their constant exposure to, engagement with, and consumption of media. For example, a male whose body does not display strength, aggression, and muscularity may be troubled during identity formation and physicality development because of incongruence with conventional gender discourse (Olivardia et al. 2004). 
Conversely, among females, a muscular body presents a body type considered masculine and inconsistent with gendered norms (Krane et al. 2010). Foucault $(1978,1983)$ coined the term subject position to indicate the relationship between discourse and power, and thus the regulation of an individual's behaviour. A subject position is a location for individuals in relation to dominant discourses (Weedon 1997). Focusing on sport specifically, a female athlete failing to conform with conventional discourses of femininity could experience limited or negative media attention, fewer sponsorship opportunities, stigmatisation or discrimination (Krane et al. 2004; Shilling and Bunsell 2009). This practice therefore 'obscures' women from the enjoyment of playing perceived non-feminine sports and/or the empowerment received by having a powerful or muscular body (Markula and Pringle 2006). Accordingly, media often trivialise female athletes and their accomplishments through representations that emphasise (hetero)sexualisation, and/or deny their sporting context (Bernstein and Kian 2013; Bruce 2015; Cranmer, Brann, and Bowman 2014; Kane 2013; Kane, La Voi, and Fink 2013; Sherry et al. 2016). By contrast, male athletes are typically represented in powerful and active poses located in the sporting context, reflecting a very different idea of what an (male) athlete can be (Cranmer et al. 2014; Lee 1992).

A potential consequence of trivialised and/or sexualised representations of female athletes is that the athletes themselves may feel their athletic identity is misrepresented. A further implication is that other athletes, particularly younger female athletes, may view such images as representations of what it is to be a 'legitimate' athlete; the performance that is expected and valued (Bissell and Zhou 2004). Given that social media has an increasing role to play in the relationship between sport athletes and consumers of all ages, Cunningham and Bright (2012) note that children have a greater exposure to sports stars, their image and behaviour, than at any other time. Thus, the version of themselves that 
athletes present to others, and in particular, to younger people is important. We may also accept Lines' $(2002,197)$ assertion that it is "too simplistic an assumption that young people will adopt the most highly profiled stars and imitate on and off field behaviour" without critique. Lines argued that young people (in her study, 15-year-olds) were not gullible and were able to distinguish between appropriate and inappropriate behaviours by adult sport stars and evaluate the athletes' moral, social and ethical mores. In this way athletic identity negotiation (or management) is an active process that entails levels of agency, consciousness and self-knowledge (Foucault 1983) on the part of the athlete themselves and by the viewer's interpretation of that material.

Rather than just considering the ways that others (media) have chosen to construct meaning behind an athletic identity or image, Krane et al. (2010) examined how elite female athletes chose to represent themselves in photos presented to younger female athletes. Seventeen of 20 women chose to be represented in their athletic attire, in confident, sporting poses and representing a positive, athletic body. When interviewed, the women noted that this was important in developing a positive role model for young girls; promoting the value of a strong and muscular body. In a follow up study, Krane et al. (2011) then investigated how young female athletes interpreted these same images. Findings indicated young girls preferred images perceived to be authentic in that the female athletes were presented in athletic settings and with appropriate sport attire. They felt these provided images they could personally relate to, and images reflecting competent and passionate sportswomen. They generally disliked images perceived as lacking motivation, poor sporting attitudes, and non-athletic poses. More recently, Barak et al. (2018) examined the way in which 17 female college athletes chose to represent themselves through self-directed photo-shoots, albeit this time without an explicit focus on targeting the image for a younger 
audience. Four themes were identified, being a female athlete highlighted athletic identities; being a female athlete described negotiations between femininity and athleticism; being a student-athlete represented stereotypes about college-athletes; and contested choices presents the social transgressions that athletes faced and navigated. The authors conclude that whilst post-feminism advocates that you can be anything you want to be, such as an athlete, social influences remain that continue to sanction what is, and is not considered controversial.

This study sought to examine the content of photographic images (the pose, location, attire, and activity undertaken) and the ways in which individual athletes constructed meaning about their identity as represented in the photographs. The potential benefits of visual methods in examining sporting and physical cultures was explored in a special edition of Qualitative Research in Sport, Exercise, and Health. In this special edition, Phoenix $(2010,94)$ noted that visual methods can "offer a different way of 'knowing' the world of physical culture", that they show the multi layered meanings of the things we see every day, and that images "are powerful in that they can do things. Images can evoke a particular kind of response" (italics in original). Images generate reactions for those that produce, as well as view them, reactions that can mirror how societies value certain types of bodies and gendered performances. The present study adopted a Foucaultian feminist framework that allows for a consideration of how gender and sport intersect in the active construction of identity. It also permits an examination of the discourses present in the constructions of meaning when athletes unpick their choice of preferred image and can tell us a great deal about the values and ideologies of sporting participation, and how these things materialise in bodies. 
Participants were asked to reflect upon experiences from throughout their athletic career and in particular to describe behaviours they considered indicative of an athletic identity. The participants were positioned as the experts in their experience of athletic identity, with the role of the researcher to support the exploration of meaning given to an image by the athletes themselves. This study extends the work of Krane et al. (2011) and Barak et al. (2018) by investigating how English based high-performance male and female athletes perform an athletic identity, and seek to act as role models, through photographic self-representation. The context of Krane et al. and Barak et al.'s research (where participants were competing at US National Collegiate Athletic Association Division 1 Universities) is different to that of the present study. We argue that while the participants based in England, were all on sporting programmes in one form or another (14 were in receipt of a University sports scholarship, two had a professional full-time contract, one a professional part-time contract, and one self-employed with sport sponsorship), they did not have had the same level of financial or sports career support as participants in the US studies. This may influence the perceived value and purpose of athletic image construction. Participants in the present study were informed that the photographic images were intended for schoolchildren aged 9-13 years, who may, or may not be athletic themselves. The following questions were addressed; 1 ) how do male and female athletes perform an athletic identity through photographic self-representation and 2) what are the key messages male and female athletes are looking to convey, as role models, through these images? Better understanding the ways in which male and female high-performance athletes adopt, interpret, or disrupt athletic identities may help challenge inequitable social relations within and beyond sporting contexts (Paechter 2006). It may also help to understand how highperformance athletes interpret messages from governing bodies, or other significant 
stakeholders, regarding expectations of their roles and responsibilities to a younger audience. This may reflect wider understandings of both expected professionalism (appropriate behaviour) and presentation (body awareness).

\section{Methods}

\section{Participants}

Participants were 12 female and six male high performance ${ }^{1}$ athletes (mean age $=$ 20.56 years, $S D=2.83)$ competing at the time of data collection. To recruit participants, all students registered on the University scholarship programme (at the lead author's institution) were invited to participate. This produced 14 participants who snowball sampled a further four participants. Participants were culturally diverse (as identified by participants own description of cultural identity) and represented a range of sports (see Table 1).

All participants consented participation in the knowledge that due to the photographic foci of the research, it would be impossible to maintain confidentiality or anonymity. In view of this understanding, participants were asked if they wished to be represented by a pseudonym or their real name. With one exception, all chose to be represented by their real name. In accordance with APA guidelines for ethical research, participants were informed of their right to withdraw consent for inclusion as a participant up until the point of publication. None of the participants chose to exercise this right.

[Insert Table 1 about here]

\section{Procedure}

\footnotetext{
${ }^{1}$ High performance in the present paper refers to competing at a national level and above
} 
Following ethical approval from the lead author's institution, the methods of data collection followed Krane et al.'s (2010) protocol. Athletes were invited to participate in a photo shoot in which they selected how they wanted to be portrayed. Athletes had artistic control over location, attire and pose - the only caveat being that the images must adhere to a PG-13 rating for safety reasons. Athletes were told that the researcher was developing a photo essay entitled 'This is a Female/Male Athlete', which would be shown to school children aged 9-13 years. Photos were taken by two final year BA (Hons) photography students, who were instructed that they could offer advice with regards lighting and framing, but not the content of the picture itself. Photo shoots ranged in duration from 3550 minutes, producing 20-30 images for participants to review.

Within a week of the photo shoot, a semi-structured interview took place with each athlete (40-80 minutes in length). The purpose of the interview was to obtain participants thoughts, feelings, and stories with regards image capture and selection, identifying images they liked and disliked with accompanying explanations. Having explored the thoughts and feelings of participants regarding the portfolio of images they had produced, participants then selected a single image they felt best captured the message they wished to convey as a sports role model, creating a caption that reinforced the intended message of this photo (Krane et al. 2010). Questions focussed on the collection of detailed, reflective, first-person accounts from participants with regards image capture and selection, giving voice to their experiences and perceptions of what it is to be an athlete (Frith and Harcourt 2011; Larkin, Watts, and Clifton 2006). They were also asked questions regarding sporting role model development, factors important for forming an (male/female) athletic identity for other younger (male/female) athletes, and how their favourite photo may or may not represent 
these factors. Athletes were given electronic copies of their photographs as a thank-you for participation in the study.

\section{Data Analysis}

\section{Photographs}

Analysis of the photos selected by participants as their preferred image followed a simplified form of descriptive content analysis in which the purpose was to record location, attire (sport specific or nonspecific), and pose (active or non-active). This followed the practice of Pedersen (2002) in his work investigating gender equity in newspaper reporting of interscholastic athletics. Participants also provided a photo caption intended to highlight the key message that they wished to convey through their preferred image. These captions were also subject to descriptive content analysis to identify the emphasised meaning or value of the caption, and whether the caption was self-determined (i.e., generated by the athlete), a pre-existing motivational quote (e.g., famous sport or leadership specific focused), or an adaptation of a pre-existing motivational quote. This first stage of descriptive analysis created a starting point for early understandings of athletic identity as portrayed by participants, including the meaning and values they wished to convey to others. These early understandings were then interrogated in greater depth during thematic analysis of participant interviews.

\section{Individual Interviews}

Analysis of interviews was guided by Braun and Clarke's (2006) thematic analysis. A consideration with thematic analysis is whether to look for and present semantic or latent themes of material; in simple terms a descriptive or interpretive level of analysis. The authors determined that whilst the photos and associated captions generated by athletes would be best represented by descriptive content analysis, interview data would be 
analysed through a latent level of analysis, in which the literature drawing upon Foucault's idea of discourse and Butler's notion of performativity would be introduced. Feminist theories informed the two research questions guiding the present study, and thus, influenced latent data analysis. As Braun and Clarke noted $(2006,84)$, and as acknowledged by the current authors, our work does not take place within a theoretical or reflexive vacuum. Thus, whilst alternative readings of the data may be produced, the focus on this work is explicitly on how athletes perform an athletic identity through photographic selfrepresentation, and the messages they look to convey to (young) others as role models.

In following Braun and Clarke's (2006) method of thematic analysis there are six stages: 1) Familiarisation with the data whereby interview transcripts were read and re-read by the authors. 2) Generating initial codes, which involved the production of codes from the data linked by a common theme or idea of relevance to the two research questions (e.g., intended messages). 3) Searching for themes, involved examining the codes to identify broader patterns of meaning. Feminist literature, in particular Foucault's idea of discourse and Butler's notion of performativity guided the identification of meanings. 4) Reviewing themes, a review of the dataset took place to ensure that latent themes best reflected the data and addressed the research questions. Themes were refined at this stage. 5) Defining and naming themes. Following detailed analysis, the scope and focus of each theme was determined along with an informative theme name. 6) Producing the written report involved contextualising the analysis in relation to feminist theories and selecting illustrative quotes considered to best reflect each theme.

\section{Trustworthiness}

To enhance trustworthiness of the data, the use of photography as a means of exploring athletic identity can go some way to limiting any power imbalance between 
researcher and participant. This is because participants in this study specifically directed image capture (rather than being directed by a photographer with their own agenda), selected their preferred images, and then spoke to what they would like to highlight in the photographs (Packard 2008). In addition, during post photo shoot interviews the interviewer asked descriptive open-ended questions, which followed the participants' dialogue, and used active listening to facilitate rapport and trust (Uphill and Jones 2007). Asking participants to identify a caption to accompany their preferred image was a procedural step intended to highlight participants intent for how they wished their selected image might be interpreted by others. This aspect of the project avoids a limitation in work such as Smith and Sanderson's (2015) examination of athletes' self-representation on Instagram; that the lack of first-person accounts can leave the interpretation of certain sensitive aspects, such as the evaluation of 'suggestive' photographs solely at the hands of the researchers. Discussing the development of each photograph in turn and reflecting on the choice of image with the athlete themselves produces a far more authentic insight into the construction of meaning.

Analysis of interview transcripts was guided by Braun and Clarke's (2006) thematic analysis. After independently coding the data, discussions took place between the three researchers with the intent of acting as critical friends, who's role was 'not to "agree" or achieve consensus but rather to encourage reflexivity by challenging each other's construction of knowledge' (Cowan and Taylor 2016, 508). This helped to construct interpretations of the data that were accepted as plausible despite possible agreements and disagreements (Smith and McGannon 2017). According to Smith (2010), knowledge is pursued in different ways because of the differences in views held by researchers about reality. Therefore, we sought to critically reflect on and seek to account for this possibility prior to the study commencing, and throughout the research process. The authors are all 
white, middle class, physically active women, lecturing on sport courses, with qualitative research specialisms. Participants were culturally diverse, a perceived strength of the present study. The lead author, who undertook all interviews, worked in a multicultural environment. At the time of data collection $46.58 \%$ of all enrolled students were of Black, Asian and Minority Ethnic origin. Prior to undertaking interviews, the interviewer undertook organisational training in cultural sensitivity to help identify and recognise any cultural bias.

\section{Results and Discussion}

The images and associated captions selected by participants are presented in Figure 1. Analysis of these reveal a tendency to select full body (16 of 18 images) action shots (15 images), situated in competitive locations (16 images). All participants chose to wear clothing associated with their sport. Of the three participants opting not to select action photos, each still had a sport marker. Karen was keen to impress the value of watching and learning from sport, selecting a photo of herself located in the football dugout. Laura chose a shot of herself entering the field of play, voicing a desire to emphasise the importance of training and preparation in determining the quality of competitive performances. Noble opted for an image of himself holding a football, looking to emphasise a physique sculpted through hard work and dedication. Captions provided were either self-determined (10), preexisting motivational quotes participants felt resonated with the intended meaning of the image (7), or an adaptation of a pre-existing motivational quote (1). Captions (and accompanying rationale provided at interview) illustrate an intended emphasis on hard work (8), psychological assets (6), technical precision (3), and encouraging participation (1). 
Aligned with the research questions, two themes were produced; 'performing an athletic identity' and 'intended messages'.

\section{Performing an Athletic Identity}

Five subordinate themes were identified that related to performing an athletic identity: 'featured in action', 'showing good technique', 'wearing of kit, and use of equipment associated with their sport', 'displaying a sporting physique', and 'demonstrating psychological assets'.

Featured in Action

The majority of participants (10 of 12 females; 5 of 6 males) selected in-action images, consistent with how they might appear in competition or training. According to Rowe $(1999,123)$, the action shot confers "status on an elite sporting body by showing it doing extraordinary things that people admire and envy"; it is perhaps for this reason that action was selected by participants in the study as they sought to produce an image that would be consumed by a younger audience (age 9-13). Action shots are considered the norm for males within mainstream media reporting (Cranmer et al. 2014). It might, therefore, be expected that male athletes in this study had a more developed frame of reference to draw upon when creating their image (Hughson 2009). Joe made explicit reference to using high profile rugby models presented in the media to inform his construction of a preferred image; 'The big superstars that they [9-13-year olds] might see on TV like Jonny Wilkinson, they'll see him doing roughly the same thing as what I'm doing in that photo, so they can kinda make the comparison.'

Through recreating a familiar image, Joe hoped that it would allow him to be read as a high-performance athlete by young people, particularly boys. Joe thought his photograph would appeal more to boys because of assumed masculine qualities of rugby. 'I think it's 
mainly a men's game. I think being a boy myself they'll look at that image and represent it to be boys'. Here, we would argue, that Joe's performance is 'intelligible' (Butler, 1990), both to himself and other boys, because it is coherent; not only with and to a sporting performance, but a gendered one also. Joe's assumptions about the gendered nature of the sport, and in turn who plays it, could be said to be informed by the discourses present in both the social and sporting arenas in which his bias around masculinity and physicality are played out.

In contrast to the way that male professional athletes are typically presented in the media, the accomplishments of female athletes are often trivialised through representations that emphasise (hetero)sexualisation, feature females in passive poses, and/or deny their sporting context (Bernstein and Kian 2013; Bruce 2015; Cranmer, Brann, and Bowman 2014; Kane 2013; Kane, La Voi, and Fink 2013; Sherry et al. 2016). In identifying how female athletes sought to challenge such stereotypical imagery, Fink, Kane and Lavoi $(2014,207)$ found that female athletes want to "be respected for what they do instead of what they look like". In a recent study, Barak et al. (2018) noted that female athletes tended to favour passive, feminine, smiling photographic self-representations over in-action photos; but did not replicate overtly sexualised images often seen in traditional sport media. They suggested that female participants may not have felt a need to depict strong female athletes in-action because they perceive the fight for equality has already been won. However, the favouring of feminine, passive, smiling images, may support a contention that the fight for equality remains, as evidenced through the production of gendered (feminine) performances (Devonport, Russell, Leflay and Conway, 2018).

The present study supports the contention that the fight for equality endures, as female athletes were keen to challenge any notion that they cannot and should not play 
certain sports. Indeed, many female athletes wished to present an action photo as a means of challenging assumptions about gender appropriate activities. As Harkirat indicated: Especially with girls, it shows girls can throw. For girls I think it will inspire them because when I was younger...I was always quite nervous because in judo they [boys/men] are supposed to be stronger than me, so it was always a bit nerve racking and then as I got older I would be throwing the boys. In a competition there was no girls and I once had to fight boys...but I ended up beating them, so that felt quite good.

Presenting performance focused images has previously been found to offer potential in depicting women in ways that resist gendered assumptions, specifically when viewed by boys aged 12-17 years old (Daniels and Wartena 2011). Krane et al. (2010) examined the choices of female athletes when given the agency to select their preferred imagery for a younger audience, overwhelmingly, they chose images that resisted stereotypical representations that are posed, passive and sexualised. Similarly, female athletes in this study also chose to privilege an in-action shot, demonstrating what they do rather than emphasising conventional norms of femininity (Knight and Giuliano 2002; Sherry et al. 2016). It could also be argued, as Miller (2010) found in his work on mix-sexed wrestling, that the way in which the female body is gendered in a combat sport is important; that gender fluidity is present. Miller found that girls both revelled in the physical strength developed through and in performances of wrestling, and in the overcoming/beating of boys; a sense of challenging the preconceived ideals of 'feminine' behaviour. Harkirat noted that boys were 'not impressed at that' in the same way that Miller's daughter noted that boys struggled with losing to girls because they are supposed to have more strength. Butler (2004) (as noted by Miller) reflects that this performative enactment (beating the boys) 
challenges assumptions of what it is to be both girl (strong) and boy (losing to a girl); a place where gender conformity and nonconformity are both experienced at the same time.

There were instances of apparent tensions when creating an image that privileged athletic identity as evidenced by illustrations of gender bias and assumptions about appropriate limits of femininity. Ebony reflected: 'It's more appealing to a girl to see me relaxed and not necessarily fast paced and aggressive... and then for the boys looking at it you see me getting into it on the ground, it's full contact'. Ebony was discussing an in-action shot and was of the belief that different aspects of the image might appeal to a young male or female audience. Ebony's reflections on the photograph might be considered indicative of deeply embedded gendered understandings of what is masculine or feminine (Mean and Kassing, 2008). Ebony was conscious that in order to appeal to females, the image had to show that it is possible to manage feminine and sporting discourses. Mean and Kassing (2008) observed that female athletes routinely feel compelled to manage gender, a constant negotiation between what is expected for more social representations of femininity and what athleticism can mean for women (Ross and Shinew 2008).

Although action shots were the norm in looking to signify athletic identity, Karen was one of three exceptions ( 2 female; 1 male). Karen discussed how sponsors often required her to be featured in action shots. This presents as an atypical experience for female athletes, with previous research suggesting that corporations using female athletes routinely highlight their sex appeal rather than their athleticism and athletic credentials (Antil, Burton, and Robinson 2012). Karen perceived being a high-performance athlete as comprising more than performance on the pitch, for her this was also about displaying a professionalism that encompassed more than physical representation. As a high-profile player in the 
women's football game, she felt less need to use the photoshoot as an opportunity to show the intended audience what she does on the pitch; preferring to convey a positive image of the women's football game as a whole. Her sense of responsibility towards promoting the women's game in a positive way, and being a positive role model, was a recurring theme throughout her interview:

At the club, I'm pretty well known, so there probably is a little bit of pressure on us to always do the right thing at the right time to promote the team 'cause probably I'm, this isn't an arrogant thing; the face of it, especially at Birmingham, so I have to be seen to do the right things at the right time most of the time, and I can't really afford to let my hair down sometimes but that's the way it goes.

Here we see Karen extend gendered performativity to represent other expectations or practices that "shape perceptions of reality" (Markula and Pringle 2006, 31). This 'regulated practice' (Foucault 1972) shapes how Karen understands her role as the figurehead for women's football at her club. This is likely to be formed by far more than just the framework of understanding at the club itself, but by a range of unwritten rules that determine certain discourses to be more legitimate than others. The language used by Karen reflects that doing 'right', and what that entails, becomes the 'object' that is recognisable by others as true/valid. Her policing of that behaviour follows an acknowledgement that some discourses become more legitimate than others (Wright 2004), get taken up more frequently (for Karen this is in the 'doing' of professional female football), and ensures that her positive image is maintained. 
Interviewees were self-critical of their images, particularly when it came to technique. All 15 participants featured in action described the importance of creating images that showcased good technique. Emily explained:

Even non-swimmers if they just have swimming lessons learn the basics - that your hands come in before they go forward on breast stroke, so I think most of them will be able to pick up on like the technical bit of hand placement in the sweep of the stroke.

Whilst Luke and Rahman take part in different sports (hurdling and cricket respectively), both selected captions emphasising technique. Luke selected 'technical track time' explaining that hurdling is 'a sport where you've got to get things right, technically right otherwise it just wouldn't work on the day'. Rahman chose 'precision' to capture the different aspects needed for a successful cricket shot. 'I chose that one because everything just aligned, looking at the ball, my feet are vertical, my hands are fully extended and I'm looking at where the ball's gone'. Consistent good technique is an expectation that audiences have of highperformance athletes, thus, ensuring images were consistent with this expectation was deemed important.

The technical demands of particular sports were subject to discussion in terms of how they were interpreted by gender. For example, Charlotte noted a comparative absence of males in race walking and wished to attract young males and females to the sport. She noted that the 'bum wiggle' in race walking was deemed too feminine among some males.

I don't know whether it's 'cause males think that they're gonna be judged cause of the way the hips move it makes your bum wiggle as well and whether the males think that they're gonna be judged for it I don't know, but in race walking it just tends to be more females than males. 
This may reflect the notion that girls often have far more 'social latitude' (Schmalz and Kerstetter 2006) in choice of sport than boys based on the construction of social (gendered) norms of the sport itself and/or the technical aspects required within them. In a further example, Harkirat, commented that women's Judo was often described as 'wudo' noting that 'pretty much all males don't like women's Judo they call it wudo'. Ebony explained that wudo was derogatory term which described 'swinging your hips in for the sake of swinging your hips in'. Both athletes wished to portray women's judo positively and so, perhaps conscious of the negative labelling associated with women's judo, both Harkirat and Ebony sought to demonstrate good technique as a way of dispelling gendered assumptions.

Wearing of Kit, and use of Equipment Associated with their Sport

The wearing of 'trophy clothes' was identified in Krane et al's (2010) study as being a signifier of being a high-performance athlete. A similar trend was observed in the current study with eleven participants selecting clothing as a clear marker of the standard of sport they compete at. Remi, for instance chose to wear the Birmingham City Football team kit for her photo shoot. Birmingham City play in the Women's Super League ${ }^{2}$, and so choosing to wear this kit communicated that she played at the top tier of the women's game. Wearing team kit represented pride in the club and was symbolic of the hard work that goes into training to earn a first team place; 'I think if I put in the hard work why can't I be the one in that blues kit playing'. Others opted to wear sports kit that symbolised their highest level of sports participation. Laura wore her England Football kit.

\footnotetext{
2 The Women's Super League (WSL) is the highest level of women's football within England and is run by the Football Association, who also manage the men's game.
} 
That's the highest level you can get to really, you know it's a privilege and honour to be able to wear your England shirt so I thought, you know, for kids who are aspiring to be young sportspeople I thought what better way to portray it than showing that you can make it to the top level? You know, anyone can do it; it's just a case of whether you have the ambition and the drive to get there.

Amy chose to wear her black belt for the photoshoot, hoping it would be read as symbolic of hard work and that high levels of attainment are achievable for everyone, rather than as 'showing off'.

It wasn't about showing it off or anything. It's something I'm proud of, it's something I worked ridiculously hard to get. I think it's a little bit of a statement on my part because it's like l've proven girls can do it, males can do it, anyone can do it if it's what they want. It's one of my best achievements so far.

Some female participants, such as Amy, felt the need to justify talking about sporting success and the wearing of trophy clothes. Amy described wearing her Karate blackbelt as symbolic of achievement rather than 'showing off' her achievements. Similarly, Karen noted she was not being arrogant when reflecting on her image as the 'face' of top-level Women's Football. Such behaviours align with notions of hegemonic femininity, defined by traits such as "submissiveness, dependency, concern over physical appearance and emotional ability" (Hardy 2015, 155). Here we see female athletes conflicted in articulating and presenting images of athletic dominance and success whilst not wishing to appear arrogant.

In a variation in the use of trophy clothes, Raman and Danielle opted to wear sports clothing, or use kit that noted sponsors. Danielle explained this decision. 
I thought for the audience though, for that age range it might be nice to showcase the clothes to the kids. I think it's great having clothes like that; that top that I'm wearing it's my arrow sponsor. What they've done is they've actually put all the names of my others sponsors on there, which is fantastic, so I get to showcase everyone and I think it's brilliant for people who start out in sport and they can see that and they think 'I really want to get there'

For Danielle, the trophy marker shows what is possible, hoped for and ultimately valued. It is an outward recognition of the hard work she has put in to get where she is now, and it fulfils a key role in the development of herself as a role model - be as good as I am and see what you can achieve. While less about gender, there is also a recognition of Danielle as an athlete with a disability, and a pride attached to achieving success (the sponsorship). In this way Danielle does 'professional' athlete.

Displaying a Sporting Physique

A sporting physique was perceived as part of an athletic identity and for Noble this meant capturing the project of training and disciplining the body. The honed physique is indicative of a hard journey, and in Noble's eyes, to be respected and admired. It is integral to the formation of an athletic identity and Noble references how he reads his own and others' physiques in this way.

When you look at my physique basically, I would say in terms of life, when you look at somebody like that, when I look at somebody like that, I think to myself, I don't just see the gym and what they are doing in the gym to get the body they have or whatever it is... to get to look the way they do, there's a lot of work that has been put in. 
However, there were gendered differences in the way that sporting physique is interpreted; female athletes recognising the need for a developed/functional sporting physique in order to be an athlete whilst acknowledging what some saw as a compromise the female apologetic (Ellison 2002) - to an authentic feminine identity. Some participants consciously decided to manipulate aspects of their appearance for the photoshoot in order to reinforce gendered expectations. Laura (Football) for instance discussed the conscious decision to wear nail varnish and mascara for the photoshoot, making specific reference for the need to prove her femininity as well as being an athlete.

I paint my nails anyway, but I did actually change them yesterday... I still think it's important to come across as girly cause there's the whole thing about women being sort of masculine if they do sport and obviously if you can show that you're still feminine and do sport then that would obviously appeal more to the girls and so I did consciously think to do my nails... I don't usually wear mascara in training but I think it was for the photos as well to help actually see my eyes, I wouldn't usually wear mascara in a game but I think just for the purpose of the photos I did that.

These behaviours are indicative of an apologetic model of resistance whereby female athletes apologise for their gendered transgressions (participating in a traditionally masculine sport) by emphasising other conventional aspects of gender presentation and performance (i.e., doing 'girly') (Ezzell 2009). Laura exemplifies both the surveillance and management practices of her own appearance in a way that then allows here to 'do' female regardless of playing a traditionally masculine sport. This process is entirely deliberate and subjective, serving to perpetuate the value of a feminine and perhaps assumed heterosexual identity, by doing 'girly', and legitimising her participation (Devonport et al. 
2018). In this way, her body is also rendered 'docile' (Foucault 1977) in the sense that Laura is regulating her body presentation to fit social mores, without the explicit need for an outside agency to enforce that.

Emily discussed conflict during her sporting career as she began to realise that musculature developed through gym work and swimming was creating a body type that might be considered inconsistent with conventional femininity. Emily's tension focused on being ready to perform and being a 'normal girl'.

I think, when I was younger and was like 14, and we started doing gym work I was like, I didn't know if like I wanted to do it, if I didn't wanna look... like have big muscles and things like that, but then obviously you can tell how it helps your performances. I feel my physique is different to most females who don't swim... I obviously noticed like I've got quite broad shoulders for a girl... especially because I am a swimmer and I think sometimes if I didn't do swimming would I just look like a normal girl like with like a normal physique. For Emily, the muscular body developed through the physical demands of the sport created feelings of conflict and distanced her from feeling like a 'normal girl' (Krane et al. 2010; Ross and Shinew 2008). Engaging in active, powerful, assertive and competitive movement (those necessary to be successful in sport) is considered masculine behaviour, therefore, females 'trespassing' into this territory risk being scrutinised and marginalised (Krane 2001; Russell 2004). Emily shows how cognisant she is of the often-competing discourses of sport and femininity, particularly at the high-performance end of sport. Although Emily was very conscious of her strength and muscular body, other female athletes reported that muscularity allows them to feel physically and mentally strong. For example, Farah was disappointed that she did not look as strong as she would like to in the 
photographs. For Farah, the embodiment of physical strength is linked to self-confidence indicating a state of preparedness for competition. Looking strong reflected an athletic identity and seen as a mechanism for psyching out opponents.

I don't think my legs look that strong... I like feeling strong because when I know that I'm fit and l've put the work in, because you can't just become strong overnight you have to really work hard at it gives me confidence in myself... I want to look strong, my body language to be positive, you don't want to look across the court and see someone who you think you can see is stronger than you, fitter than you... it's how you perceive yourself compared to others so I would back myself more.

For Farah, there is a clear 'functionality' (Russell 2004) to her physicality both in terms of presentation and in and through her performances, allowing herself to feel justified that her shape and size creates a context for success. It also allows her the opportunity to create a context that is deliberate in shaping confidence. What we do not fully understand is if or how this body confidence is maintained once off the tennis court.

With one exception, male athletes did not report conflict between athlete identity and masculine identity. Luke expressed a desire to become bigger and more muscular; explaining that working in a personal training environment had shaped his ideal masculine body. He noted how his coach advised him to lose some muscle mass to improve his performance on the track. As with Emily, Luke's conflict emerged between having the right body for optimal sport performance and one desired for appearance related reasons.

Me and my coach had a bit of a discussion last year because I like a lot of gym work; I work in a gym and that's what I'm qualified as, I put on quite a lot of muscle last year and I was seen as too heavy. I'm not the heaviest person, I 
weigh 74 kilo which is about eleven and a half stone, so carrying that round for a 400-metre run, that's quite heavy, so he told me to lose a little bit of muscle. I'd like to put some weight on...probably about 3 or 4 kilo heavier I guess. It's just a bit of ego I think, just for the fact I like bigger and better. For male athletes, the development of a muscular sporting physique is seen as a marker of masculine and sporting identity (Messner 2012). For Luke, being told by his coach he needed to drop weight and lose muscle mass was seen as problematic for maintaining what he considered to be an idealised masculine body. As evidenced in previous research, a male whose body does not display strength, aggression, and muscularity may be uncomfortable with this because of incongruence with conventional gender discourse (Olivardia et al. 2004).

\section{Demonstrating Psychological Assets}

In articulating identity, emphasising hard work was a common feature across the interviews. Male and female athletes consistently sought to highlight the importance of hard work for attaining sporting goals, a finding also evidenced by Krane et al. (2010). There was a desire to encourage young people to work hard to achieve meaningful goals whatever the context. Remi wanted her image to capture the hard work and sacrifice that goes into becoming a high-performance athlete, particularly the hours invested when no-one is watching. Although triumphs occur on match days in front of an audience, for Remi, it is the 'stuff that's done behind the scenes' that makes success possible. Remi explained that the empty stands in the background of her photo emphasise the sometimes-lonely journey towards success that requires self-discipline. This discourse, one of sacrifice and discipline, creates a particular subject position for Remi. The language used here shapes a 'regime of truth' (Foucault 1973) that specifies what can/should be done at particular places and at 
particular times. As Shogan $(1999,47)$ noted in her work with female rowers, it is important for researchers to not just simply describe the experience of athletes and assume that this is their identity, but to explore how the experiences are the consequences of discourses that make "possible these experiences and not others". For Remi, the role performed is one of the athlete; someone who would and should do this work in isolation. She uses this to present an ideal to others shaping what is expected from and for them.

Mental strength was also regarded as essential in both training and competition. Emily explained the inter-relationship between physical and mental strength suggesting: 'No matter how like physically fit you are, if you're not mentally fit then you won't get your, like, highest ability you can get and achieve what you're meant to achieve'.

Emily tried to capture psychological strength through her picture of a high intensity swim. Her caption of 'determined' reflected the combination of physical effort and mental focus required at high levels of sport. Giuliano, Turner, Lundguist, and Knight (2007) argued that female role models can be empowering and may impart lessons about how to navigate the challenging terrain of women's sport. Mental strength and overcoming adversity both within sporting contexts and beyond represents a powerful message for young people (Krane et al. 2010). Messner (1988) has suggested that this is a message consistently given to boys however it is equally important to girls.

Being engrossed in the sport activity and appearing unaware of the camera was the effect sought by Danielle 'I quite like where I'm not looking at the camera, so it looks like I'm really focused and in that moment, because at the end of the day elite sport is serious'. Danielle's chosen caption of 'Aiming for gold' is also significant in this context as it signifies the level of focus required to succeed in major sporting tournaments. Although Danielle's explanation of her image does not make explicit reference to gender, her disinterest in the 
camera denies what has often been referred to as the male gaze (Mulvey 1975; Caudwell 2008). Dismissing the viewer is a convention more traditionally associated with images of males (Mason 1992; Morrison and Halton 2009). In her interview, Danielle demonstrated an awareness of the tendency to focus on the appearance of female athletes, particularly when they are conventionally feminine. This was something that Danielle had experienced personally. She explained: 'I started getting quite a lot of coverage and it sounds really really awful, but I do think um there quite a lot of aesthetics, you know, 'the face fits', like, we've got some great people in our sport but because they might be slightly larger than your stereotypical athlete they didn't get the coverage'.

\section{Intended Messages}

This second theme captured the messages that athletes wished to convey as role models for younger audiences. It reflected the perceived role of athletes in attracting individuals to participate in, or spectate at their respective sports, and how their image communicated this message. This comprised two second-order themes: 'give sport a go', and the 'importance of hard work'. These two themes illustrate continued existence of female/athlete paradox through the messages female athletes looked to convey. Many female athletes felt the need to balance their athleticism with femininity (Barak et al. 2018; Krane et al. 2011). Further illustrating the power of heteronormative standards and the policing of these through ongoing self-surveillance, findings also highlight the ways in which male participants seek to adhere to narrow masculine ideals (Butler 1993; Foucault 1972). 
One of the consistent messages athletes hoped to convey to a younger audience was to give sport a go, whether that be the sport profiled or wider sporting activities. Amy wanted her image to encourage young people to do whatever inspires them:

I'd hope that if a younger person saw that it would be an inspiration to do something, like, if not do karate, then take in some other sport they're interested in... I would like kids to do whatever they want in their sport, get to wherever they want to be.

Individuals in sports they described as minority sports sought to encourage participation in their sport. For example, Mimi explained 'no one really knows about rhythmic gymnastics because it's quite a minority sport so this photo could show them something different that they could get involved in' whilst Danielle noted 'it would actually be quite nice to reach out to the girls and say look, you know...it's not a very common sport, not as well-known as a lot of the others, but you know, it is quite fun, it looks cool, it's great to be involved in'.

From a role model perspective, the athletes are tapping into the belief that sportspeople can, and do influence young people into being physically active (May 2009; Reid 2017). While this belief is widely accepted, this should also be tempered by the perceived relevance of that athlete (Lyle 2009) to an individual based on matching of dimensions of identity (Bricheno and Thornton 2007; Gibson 2004, May 2009). Perhaps in recognition of the personal battle she had to endure to access karate, Amy captioned her photograph 'strength in personality'. Although positive changes are occurring in the sport, Amy wanted to get the message across that:

Overcoming barriers isn't easy, but it's down to one person to fight their way through and come out on top, ultimately stronger for it... there are some girls that think "oh 
yeah I wanna do that because she's doing" it and I would hope that girls seeing this would be like "that's a girl I can do that".

It seems that by seeking to attract more females to such sports, females were addressing a need to feel less of a minority group, increase a sense of belonging, and challenge notions of masculinity surrounding these sports. The media, for example, present sports as if there are masculine (e.g., football and Judo) and feminine (e.g., gymnastics and figure skating) sports, aligning with traditional expectations of male and female athletes (Koivula 1995). This makes it more difficult to break traditional gender barriers allowing women to participate in masculine sports and men to participate in feminine sports. In fact, many female athletes are only accepted by society and receive coverage in the media if they participate in traditionally feminine sports (Coche and Tuggle 2016). Thus, although ostensibly Amy's message appears to be empowering and inspirational to other females who might find themselves in the position of being a minority in a particular sport, it denies the social, structural and policy changes that are needed to increase opportunities to girls and women and situates the battle for access and acceptance at the level of the individual. There was evidence to support the notion that gender intersects other dimensions of identity to influence sports participation. For example, Black judoka Ebony noted, 'in England you don't really see many black players... the most you'll see on the team is France, so when I go abroad most of the time people think that I'm French'. Black feminists Crenshaw (1991) and Collins (1991) introduced the concept of intersectionality to explain how interacting dimensions of identity (e.g., class, ethnicity, nationality, race and sexuality) can lead to distinct forms of marginalisation, oppression and disempowerment. As noted by Raman, there was a general view that being visible in a sport could encourage those with shared identity to give [their] sport a go: 
I'm Indian so in my county [regional area] I'm probably one of two so, I definitely think that it gives the impression that erm it can be done if you're that race ... I don't see now a lot of Asians playing Cricket throwing themselves around everywhere. So I think it shows the message that you can do it, erm it's not out of your reach. This belief of 'see it to be it' was also endorsed by Luke who noted:

I'd try to direct the image more towards boys because, not just in the region but in the whole country there's no boy hurdlers, or men hurdlers... it's really depressing because I've no training partner and people see it as a girlie event. Importance of Hard Work

The importance of hard work emerged as another strong message athletes wanted to convey to young people. Although hard work was seen as essential for creating an athletic identity, participants hoped the message of hard work would extend beyond sport and into other areas of young people's lives. Farah explained 'I believe that nobody is born with the right to succeed, we are a result of the things we do'. The sentiment was echoed by Ben; 'putting the effort in tends to normally come out on top in the end, maybe not straight away but if you carry on it will'.

Remi wanted to be a positive role model; for her demonstrating a particular work ethic; 'whatever it is in life you want to do, hard work is the core of everything. We all need this in our life to get to where you want'.

Changeable weather on the day of Remi's photoshoot produced a backdrop that she felt reinforced her intended message; storm clouds contrasted with a rainbow was perceived by Remi as representative of weathering the storm, working hard and enjoying the subsequent success at the end of the rainbow. Other athletes, such as Harkirat noted a similar sporting trope in that 'you make your own luck, the harder you work the more luck 
you have'. For her, the link between effort and persistence comes from a determined work ethic and the potential for success; clear motivational and strong role model qualities to have.

For Emily, her sense of determination came more from her physical expressions, in contrast to other athletes' choices to appear relaxed and having fun.

It's not like a pleasant look that I've got on my face, it is like "I want to do this", it's like I'm looking like I want to do it, it's something I want to do rather than something I'm just doing for fun, so I hope they pick up on that... I hope they pick up on like the effort as well, like how much effort goes into it... that's probably it, it's like the effort and the determination.

In the present study, participants expressed a hope that messages conveyed through their photos (and in some instances associated captions) regarding hard work, were transferable to young people who may consume the image. Athletes wished to convey a widely held perception that through sport, one can gain skills and values necessary to be successful in other avenues of life (Lines 2001). The wearing of trophy clothes, such as national kit, or sponsored kit was considered by some to be a signifier of hard work, and a reward for the training and effort invested in sport.

Limitations and Conclusions

Participants included in the present study are culturally diverse and include an athlete with a disability. Whilst we suggest this is a strength of the present study, we urge caution in interpreting the findings as representative of athletes with a disability, and Black and minority ethnic (BAME) athletes due to the relatively low participant numbers representative of these demographics. We recommend that future research replicates this study protocol targeting BAME athletes and athletes with a disability, as participation rates 
among these groups in England is lower than dual ethnicity or white individuals and nondisabled peers (Bi 2011; Sport England 2018). We recognise that the messages athletes intended to convey to a young audience may not be received, with alternative interpretations of the images. As such, examining how the images are interpreted by alternative audiences presents a future line of enquiry. Furthermore, it is important to acknowledge that the known audience for the photos was young people, and this is likely to have influenced the way participants chose to present themselves (Krane et al. 2018).

To conclude, sporting role models are thought to have a significant impact on the beliefs and actions of individuals (Vescio, Wilde, and Crosswhite 2005). Many athletes in the study were acutely aware of their status as a role model and embraced the opportunity to try and influence young people in a positive way. Participants sought to champion their sport and the physical and psychological qualities that participation produces. In doing so, for many participants gendered performances were evident in both the production and interpretation of the images produced. The significance of this is that whilst role models have been shown to influence young people in partaking in sport (May 2009; Reid 2017), this is dependent on the perceived relevance of that athlete based on matching of dimensions of identity (Gibson 2004; Bricheno and Thornton 2007; May 2009). In other words, if sports imagery of male and female athletes consistently conforms with conventional notions of masculinity and femininity, it may fail to inspire and attract those who do not conform to such notions. Ultimately, whilst the images used to present sporting 'role models' may be influenced by governing body remits or funder guidelines, it is important to remember that individual sport performers must have their vision of an athletic identity represented too, and that heterogeneity of sports images may encourage a more individuals to 'give sport a go'. 


\section{References}

Antil, J., Burton, R., and Robinson, M. 2012. "Exploring the challenges facing female athletes as endorsers". Journal of Brand Strategy 1 (3): 292-307.

Barak, K. S., Krane, V., Ross, S. R., Mann, M. E., and Kaunert, C. A. 2018. "Visual negotiation: How female athletes present intersectional identities in photographic selfrepresentations". Quest 1-21. doi:10.1080/00336297.2018.1461661

Bernstein, A., and Kian, E. M. 2013. "Gender and sexualities in sport media." In Routledge handbook of sport communication, edited by P. Pedersen, 319-327. London: Routledge.

Bi, S. 2011. "Contemporary policy debate: sporting equality for BME communities." Journal of Policy Research in Tourism, Leisure and Events. 3 (2): 204-208. doi:10.1080/19407963.2011.555461

Bissell, K. L., and Zhou, P. 2004. "Must see TV or ESPN: Entertainment and sports media exposure and body image distortion in college Women." Journal of Communication. 54 (1): 5-21. doi:10.1111/j.1460-2466.2004.

Braun, V., and Clarke, V. 2006. "Using thematic analysis in psychology". Qualitative Research in Psychology. 3 (2): 77-101. doi:10.1191/1478088706qp063oa

Bricheno, P., and Thornton, M. 2007. "Role model, hero or champion? Children's views concerning role models". Educational Research. 49 (4): 383-396. doi:10.1080/00131880701717230

Bruce, T. 2015. "New rules for new times: Sportswomen and media representation in the Third Wave." Sex Roles. 74 (7-8): 361-376. doi:10.1007/s11199-015-0497-6.

Butler, J. 1990. Gender trouble: Feminism and the subversion of identity. New York: Routledge. 
Butler, J. 1993. Bodies that matter: On the discursive limits of sex. New York: Routledge.

Butler, J. 2004. Undoing gender. New York: Routledge

Caudwell, J. 2008. “Girlfight: Boxing women”. Sport in Society. 11 (2): 227-239.

Coche, R. and Tuggle, C. A. 2016. “The women's Olympics?: A gender analysis of NBC's coverage of the London 2012 Summer Games". Electronic News. 10 (2): 121-138. doi:10.1177/1931243116647770

Collins, P. H. 1991. Black feminist thought: Knowledge, consciousness, and the politics of empowerment. New York: Routledge.

Cowan, D., and Taylor, I. M. 2016. "I'm proud of what I achieved; I'm also ashamed of what I done: A soccer coach's tale of sport, status, and criminal behaviour". Qualitative Research in Sport, Exercise and Health. 8: 505-518. doi:10.1080/2159676X.2016.1206608

Cranmer, G. A., Brann, M., and Bowman, N. D. 2014. "Male athletes, female aesthetics: The continued ambivalence toward female athletes in ESPN's The Body Issue." International Journal of Sport Communication. 7 (2): 145-165. doi:10.1123/IJSC.20140021.

Crenshaw, K. W. 1991. "Mapping the margins: Intersectionality, identity politics, and violence against women of color. Stanford Law Review. 43: 1241-1299. doi:10.2307/1229039

Cunningham, N., and Bright, F. 2012. "The Tweet is in your court: Measuring attitude towards athlete endorsements in social media". International Journal of Integrated Marketing Communications. 4: 73-87. doi:10.13140/2.1.4644.6724

Daniels, E., and Wartena. H. 2011. "Athlete or sex symbol: What boys think of media representations of female athletes." Sex Roles. 65 (7-8): 566-579. doi:10.1007/s11199-011-9959-7. 
Devonport, T., Russell, K., Leflay, K., and Conway, J. 2018. “Gendered performances and identity construction among UK female soccer players and netballers: A comparative study." Sport in Society. 1-17. doi:10.1080/17430437.2018.1504773

Ellison, J. 2002. “Women and sport: An examination of advertisements between 1950 and 2002." Canadian Woman Studies. 21 (3): 77-82.

Ezzell, M. B. 2009 “"'Barbie Dolls" on the pitch: Identity work, defensive othering, and inequality in women's rugby." Social Problems. 56 (1): 111-131. doi:10.1525/sp.2009.56.1.111

Fink, J. S., Kane, M. J., and LaVoi, N. M. 2014. "The freedom to choose: Elite female athletes' preferred representations within endorsement opportunities." Journal of Sport Management. 28 (2): 207-219. doi:10.1123/jsm.2013-0101

Foucault, M. 1972. The archaeology of knowledge and discourse on language. New York: Pantheon Books.

Foucault, M. 1973. The birth of the clinic. London: Tavistock.

Foucault, M. 1977. Discipline and punish: The birth of the prison. New York: Pantheon Books. Foucault, M. 1978. The history of sexuality, volume 1: An introduction. London: Penguin Books.

Foucault, M. 1983. "The subject and power", In Michel Foucault: Beyond Structuralism and Hermeneutics, edited by H. L. Dreyfuss and P. Rabinow. Chicago, IL: University of Chicago Press.

Frith, H., and Harcourt, D. 2007. “Using photographs to capture women's experiences of chemotherapy: Reflecting on the method." Qualitative Health Research. 17: 13401350. doi:10.1177/1049732307308949. 
Gibson, D. 2004. "Role models in career development: New directions for theory and research", Journal of Vocational Behaviour. 65: 134- 156. doi:10.1016/S00018791(03)00051-4

Giuliano, T. A., Turner, K. L., Lundguist, J. C., and Knight, J. L. 2007. “Gender and the selection of public athletic role models." Journal of Sport Behavior. 30 (2): 161-198.

Hardy, E. 2015. “The female 'apologetic' behavior within Canadian women's rugby: Athlete perceptions and media influences." Sport in Society. 18 (2): 155-167. doi:10.1080/17430437.2013.854515.

Hughson, J. 2009. "On sporting heroes", Sport in Society. 12 (1): 85-101. doi:10.1080/17430430802472327.

Kane, M. J. 2013. "The better sportswomen get, the more the media ignore them." Communication and Sport. 1 (3): 231-236. doi:10.1177/2167479513484579.

Kane, M. J., La Voi, N. N., and Fink, J. S. 2013. “Exploring elite female athletes' interpretations of sport media images: A window into the construction of social identity and 'selling sex' in women's sport." Communication and Sport. 1 (3): 269-298. doi:10.1177/2167479512473585.

Knight, J. L., and Giuliano, T. A. 2001. "“He's a Laker, she's a "looker": The consequences of gender stereotypical portrayals of male and female athletes by the print media." Sex Roles. 45 (1/2): 217-229. doi:10.1023/A:1013553811620

Koivula, N. 1995. "Ratings of gender appropriateness of sports participation: Effects of gender-based schematic processing". Sex Roles. 33: 543-557. doi:10.1007/BF01544679 
Krane, V. 2001. "We can be athletic and feminine, but do we want to? Challenging hegemonic femininity in women's sport." Quest. 53 (1): 115-133. doi:10.1080/00336297.2001.10491733.

Krane, V., Choi, P., Baird, S., Aimar, C., and Kauer, K. 2004. "Living the paradox: Female athletes negotiate femininity and muscularity". Sex Roles. 50 (5/6): 315-329. doi:10.1023/B:SERS.0000018888.48437

Krane, V., Ross S. R., Miller M., Rowse J. L., Ganoie K., Andrzejczyk J. A, and Lucas C. B. 2010. "Power and focus: Self-representation of female college athletes." Qualitative Research in Sport and Exercise. 2 (2): 175-195. doi:10.1080/19398441.2010.488026.

Krane, V., Ross S. R., Miller M., Ganoe K., Lucas-Carr C., and Barak K. S. 2011. ““It's cheesy when they smile:" What girl athletes prefer in images of female college athletes." Research Quarterly for Exercise and Sport. $82 \quad$ (4): 755-768. doi:10.1080/02701367.2011.10599812.

Larkin, M., Watts, S., and Clifton, E. 2006. “Giving voice and making sense in Interpretative Phenomenological Analysis", Qualitative Research in Psychology. 3 (2): 102-120. doi:10.1191/1478088706qp062oa

Lee, J. 1992. “Media portrayals of male and female Olympic athletes: Analyses of newspaper accounts of the 1984 and the 1988 Summer Games." International Review for the Sociology of Sport. 27 (3): 197-219. doi:10.1177/101269029202700301

Lines, G. 2001. "Villains, fools or heroes? Sports stars as role models for young people". Leisure Studies. 20: 285-303. doi:10.1080/02614360110094661.

Lines, G. 2002. "The sports star in the media: The gendered construction and youthful consumption of sport personalities". In Power games: A critical sociology of sport, edited by J. Sugden and A. Tomlinson, 196-215. London: Routledge. 
Lyle, J. 2009. Sporting success, role models and participation. A policy related review. Edinburgh, sportscotland.

Markula, P., and Pringle, R. 2006. Foucault, sport and exercise: Power, knowledge and transforming the self. London: Routledge.

Mason, G. 1992. "Looking into masculinity". Social Alternatives. 11 (1): 27-32.

May, R. 2009. "The good and bad of it all: Professional Black male basketball players as role models for young Black male basketball players". Sociology of Sport Journal. 26 (3): 443-461.

McGannon, K. R., and Spence, J. C. 2012. "Exploring news media representations of women's exercise and subjectivity through Critical Discourse Analysis." Qualitative Research in Sport, Exercise and Health. 4 (1): 32-50, doi:10.1080/2159676X.2011.653503

Meân, L. J., and J. W. Kassing. 2008. "'I would just like to be known as an athlete': Managing hegemony, femininity, and Heterosexuality in female sport." Western Journal of Communication. 72: 126-144. doi:10.1080/10570310802038564

Messner. M. 1988. "Sports and male domination: The female athlete as contested ideological terrain." Sociology of Sport Journal. 5 (3): 197-211. doi:10.1123/ssj.5.3.197.

Miller, S. A. 2010. "Making the boys cry: The performative dimensions of fluid gender." Text and Performance Quarterly. 30 (2): 163-182, doi:10.1080/10462931003658099

Morrison, T.G. and Halton, M. 2009. "Buff, tough and rough: Representations of muscularity in action motion pictures". The Journal of Men's Studies. 17 (1): 57-74. doi:10.3149/jms.1701.57

Mulvey, L. 1974. Visual pleasure and narrative cinema, London: British Film Industry. 
Olivardia, R., Pope, H. G., Borowiecki, J. J, and Cohane, G. H. 2004. "Biceps and body image: The relationship between muscularity and self-esteem, depression, and eating disorder symptoms." Psychology of Men and Muscularity. 5 (2): 112-120. doi:10.1037/1524-9220.5.2.112

Packard, J. 2008. "'I'm gonna show you what its really like out here': The power and limitation of Participatory Visual Methods." Visual Studies. 23 (1): 63-77.

Paechter, C. 2006. "Masculine femininities/feminine masculinities: Power, identities and gender". Gender and Education. 18 (3): 253-262. doi: 10.1080/09540250600667785.

Pedersen, P. M. 2002. “Examining equity in newspaper photographs: A Content Analysis of the print media photographic coverage of interscholastic athletics." International review for the Sociology of Sport. $37 \quad$ (3-4): 303-318. doi:10.1177/1012690202037004895

Phoenix, A. 1997. "Youth and gender: New issues, new agenda." Young. 5 (3): 2-19. doi:10.1177/110330889700500301.

Phoenix, C. 2010. "Seeing the world of physical culture: the potential of visual methods for qualitative research in sport and exercise", Qualitative Research in Sport and Exercise. 2 (2): 93-108, doi:10.1080/19398441.2010.488017Reid, H. 2017). “Athletes as heroes and role models: An ancient model", Sport, Ethics and Philosophy. 11 (1): 40-51. doi:10.1080/17511321.2016.1261931

Ross, S. R., and Shinew, K. J. 2008. "Perceptions of women college athletes on sport and gender." Sex Roles. 58 (1-2): 4-57. doi: 10.1007/s11199-007-9275-4.

Rowe, D. 1999. Sport, Culture and the media. Buckingham: Open University Press. 
Russell, K., M. 2004. “'On versus off the pitch': The transiency of body satisfaction among female rugby players, cricketers, and netballers." Sex Roles. 51: 561-574. doi: $10.1007 / \mathrm{s} 11199-004-5466-4$

Schmalz, D. L., and Kerstetter. D. L. 2006. “Girlie girls and manly men: Children's stigma consciousness of gender in sports and physical activities". Journal of Leisure Research. 38 (4): 536-577. doi:10.1080/00222216.2006.11950091

Sherry, E., Osborne, A., and Nicholson, M. 2016. "Images of sports women: A review." Sex Roles. 74 (7-8): 299-309. doi: 10.1007/s11199-015-0493-x.

Shilling, C and Bunsell, T. 2009. "The female bodybuilder as a gender outlaw", Qualitative Research in Sport and Exercise. 1 (2): 141-159. doi:10.1080/19398440902909009

Shogan, D. 1999. The making of high performance athletes: Discipline, diversity and ethics. Toronto: University of Toronto Press.

Smith, M. F. 2010. Research methods in sport. Exeter, UK; Learning Matters.

Smith, B., and McGannon, K. R. 2017. “Developing rigor in qualitative research: Problems and opportunities within sport and exercise psychology". International Review of Sport and Exercise Psychology. 11(1): 101-121. doi:10.1080/1750984X.2017.1317357

Smith, L. R., and Sanderson, J. 2015. “'I'm going to Instagram it!' An analysis of athlete selfpresentation on Instagram." Journal of Broadcasting \& Electronic Media. 59 (2): 342358, doi:10.1080/08838151.2015.1029125

Sport England. 2018. Active Lives survey https://www.sportengland.org/media/13217/vmass-markets-digital-content-editorial-team-active-lives-march-2018-active-livesadult-survey-nov-16-17-final.pdf. 
Uphill, M. and Jones, M. 2007. "Antecedents of emotions in elite athletes." Research Quarterly for Exercise and Sport. 78 (2): 79-89. doi:10.1080/02701367.2007.10599406

Vescio, J., Wilde, K., and Crosswhite, J. J. 2005. “Profiling sport role models to enhance initiatives for adolescent girls in physical education and sport." European Physical Education Review. 11 (2): 153-170. doi:10.1177/1356336X05052894.

Weedon, C. 1996. Feminist practice and Poststructuralist theory $\left(2^{\text {nd }}\right.$ ed). New Jersey: WileyBackwell.

Wright, J. 2004. "Post Structural methodologies: The body, schooling and health", In Critical inquiry and problem solving in physical education, edited by J. Wright., D Macdonald and L. Burrows, London: Routledge. 